\title{
Most children with cancer are not enrolled on a clinical trial in Canada: a population- based study
}

\author{
Jason D. Pole ${ }^{1}$, Randy Barber ${ }^{2}$, Rose-Émilie Bergeron ${ }^{3}$, Anne Sophie Carret ${ }^{4}$, David Dix ${ }^{5}$, Ketan Kulkarni ${ }^{6}$, \\ Emilie Martineau ${ }^{7}$, Alicia Randall ${ }^{6}$, David Stammers ${ }^{8}$, Caron Strahlendorf ${ }^{5}$, Douglas R. Strother ${ }^{9}$, \\ Tony H. Truong ${ }^{9}$ and Lillian Sung ${ }^{10,11^{*}}$
}

\begin{abstract}
Background: Primary objective was to describe the proportion of children newly diagnosed with cancer enrolled on a therapeutic clinical trial. Secondary objectives were to describe reasons for non-enrollment and factors associated with enrollment on trials.

Methods: In this retrospective cohort study, we included children newly diagnosed with cancer between 0 and 14 years of age and diagnosed from 2001 to 2012. We used data from the Cancer in Young People in Canada (CYP-C) national pediatric cancer population-based database. CYP-C captures all cases of pediatric cancer (0-14 years) diagnosed and treated at one of the 17 tertiary pediatric oncology centers in Canada. Non-enrollment was evaluated using univariate and multiple logistic regression analysis.

Results: There were 9204 children with cancer included, of whom 2533 (27.5\%) were enrolled on a clinical trial. The most common reasons cited for non-enrollment were lack of an available trial (52.2\%) and physician choice (11.2\%). In multiple regression, Asian and Arab/west Asian race were associated with lower enrollment $(P=0.006$ and $P=0.032$ respectively). All cancer diagnoses were more likely to be enrolled compared to astrocytoma and children with acute lymphoblastic leukemia had an almost 18-fold increased odds of enrollment compared to astrocytoma $(P<0.0001)$. Greater distance from the tertiary care center was independently associated with non-enrollment $(P<0.0001)$.

Conclusions: In Canada, 27.5\% of children with cancer are enrolled onto therapeutic clinical trials and lack of an available trial is the most common reason contributing to non-enrollment. Future research should better understand reasons for lack of trial availability and physician preferences to not offer trials.
\end{abstract}

Keywords: Clinical trial enrollment, Children, Cancer, Canada, Population-based

\section{Background}

There has been considerable controversy about whether enrollment on clinical trials confers a benefit to pediatric cancer patients. Several retrospective studies have concluded that patients enrolled on clinical trials have better outcomes compared with patients not enrolled on clinical trials [1]. However, as highlighted by Peppercorn, [1] these studies had important limitations regarding

\footnotetext{
* Correspondence: lillian.sung@sickkids.ca

${ }^{10}$ The Hospital for Sick Children, 555 University Avenue, Toronto M5G 1X8, Canada

${ }^{11}$ Child Health Evaluative Sciences, 686 Bay Street, Toronto M5G 0A4, Canada Full list of author information is available at the end of the article
}

adjustment for potential confounders and restriction to those who would have met trial eligibility and thus, there is uncertainty about the overall benefit of trial participation. In contrast, a recent study suggested that trial participation may be associated with more infectious toxicity in children with acute myeloid leukemia [2]. It is important to emphasize there are other benefits to trial participation other than the potential for improved outcomes, such as contribution to scientific knowledge, potential to help future patients and satisfaction of knowing participants have helped others [3].

Before understanding whether patients enrolled on trials have better outcomes, it is also important to 
understand whether pediatric cancer patients are enrolling on trials. Failure to enroll on trials may be due to multiple factors. Possibilities include that a clinical trial for a specific diagnosis does not exist, a trial has not received regulatory or ethics approval at the institution, the institution has chosen not to activate the trial, the patient did not meet eligibility criteria, an eligible patient was not offered the trial for logistical, physician or patient-related factors or because the patient or family refused the trial [1].

The proportion of children newly diagnosed with cancer enrolled on trials is reported to range from 38\% [4] to $86 \%$ [5]. According to the Children's Oncology Group, more than $60 \%$ of young patients with cancer are enrolled in trials [6]. However, there is confusion about whether these estimates reflect all children who present with cancer, or just those who are offered trials. For National Cancer Institute-sponsored trials, Canadian institutions have additional regulatory hurdles compared to US institutions. After these trials are approved by the relevant US agencies (such as the Clinical Trials Evaluation Program and the Central Institutional Review Board), they subsequently must be approved by Health Canada and local Research Ethics Boards before Canadian sites can activate them. It is uncertain whether lack of trial availability has an important impact on the proportion of non-enrolling pediatric cancer patients in Canada. It is important to note that clinical trials include both therapeutic trials directed at cancer treatment and supportive care trials focused on reducing toxicity or improving quality of life. This study is focused on enrollment on therapeutic trials.

In order to address the question of enrollment to therapeutic clinical trials, we used the Cancer in Young People in Canada (CYP-C) database, a national pediatric cancer population-based database. The primary objective was to describe the proportion of children newly diagnosed with cancer enrolled on a therapeutic clinical trial. Secondary objectives were to describe reasons for non-enrollment and factors associated with enrollment on trials.

\section{Methods}

Population of interest and sampling methods

Eligibility Criteria: (1) Children with newly diagnosed cancer 0 to 14 years of age at diagnosis; (2) Diagnosed between January 1, 2001 and December 31, 2012; (3) Diagnosis and treatment at one of the 17 pediatric oncology centers in Canada and entered into CYP-C; and (4) Diagnosis included in the International Classification of Childhood Cancer (ICCC), third edition [7]. Diagnoses eligible for ICCC are those with malignant behavior and non-malignant intracranial and intraspinal tumors [7]. We excluded patients in which it was unknown whether they were enrolled on a clinical trial for the treatment of the initial cancer diagnosis.

\section{Data source}

The data source was CYP-C. CYP-C is a populationbased registry that captures all cases of pediatric cancer diagnosed and treated at one of the 17 tertiary pediatric oncology centers in Canada. These 17 centers provide virtually all care for children with cancer $<15$ years of age.

CYP-C is a publicly available dataset; application for data utilization can be submitted through the $\mathrm{C}^{17}$ Council website (www.c17.ca/index.php?cID=70). Patients diagnosed between 0 and 14 years of age since 2001 are included and are followed for 5 years after the first or any subsequent malignancy eligible for inclusion in CYP-C. For centers in Ontario $(n=5)$, data are transferred to CYP-C from the Pediatric Oncology Group of Ontario (POGO) Networked Information System (POGONIS), a provincial population-based registry that includes similar, but not identical data elements to CYPC. POGONIS captures $96-98 \%$ of children 0-14 years of age diagnosed with cancer as compared with the Ontario Cancer Registry [8]. For centers outside of Ontario $(n=12)$, data are entered directly into CYP-C. Elements captured by CYP-C include demographic variables (sex, date of birth, postal code and race), diagnostic details, times to diagnosis and treatment, details of treatment plans and outcomes such as relapse, second malignancy and death.

Enrollment on a therapeutic trial is explicitly collected by both databases. At each center, identification of patients who are enrolled on a clinical trial is abstracted from the medical records. Only enrollment on a trial at the initial diagnosis was used for this analysis and not later during the course of therapy.

Achieving high quality data has been an objective of the program since inception and the following have been implemented to maximize data accuracy. A community of practice composed of each site's data manager was established. The group meets monthly by teleconference to discuss difficult cases and face-to-face annually to further solidify training. Site audits to each site outside of Ontario have been conducted and more specifically, the section on enrollment on trials was included in the audit. Data quality issues have not been identified for this element (personal communication, Randy Barber, April 23, 2017).

For the secondary objective, related to describing reasons for non-enrollment, the CYP-C database consistently collected the stated reasons for non-enrollment using a standardized list throughout the study period. Reasons for failure to enroll on a clinical trial were categorized as follows: (1) Language barrier, trial not offered; 
(2) No available trial at the time; (3) Not eligible for any available trial; (4) Physician choice; (5) Refused therapy; (6) Refused to participate in proposed trial; (7) Other, specify; and (8) Information not available. Only one reason could be selected. Free text options could be indicated if the "Other" category was chosen. If not eligible was chosen, it was implied that a trial was available for that patient based upon diagnosis and age. In contrast, the POGONIS database collected reasons for non-enrollment using a standardized list only for patients diagnosed after 2010. Thus, only data from the 12 non-Ontario centers was included for the description of reasons for non-enrollment.

\section{Statistical plan}

Primary analyses were descriptive. Categorical variables were compared between those enrolled and not enrolled on trials using Chi square tests.

In order to describe factors associated with enrollment, the following variables were examined: age at diagnosis $(<1,1-4,5-9$ and 10-14), sex, race (as collected by CYP-C), diagnosis era $(<2007$ and $\geq 2007$; midpoint of study), and sociodemographic factors. Sociodemographic factors were determined by using postal codes at diagnosis to obtain distance to the nearest tertiary care pediatric cancer center and arealevel socioeconomic status by linking to census data. Full 6 digit postal codes were available for all provinces except for British Columbia in which only 3 digit postal codes were available. We used the Statistics Canada Postal Code Conversion File software (PCCF+, Version $4 \mathrm{~J})$ and linked the postal code at the time of diagnosis to a 2001 census dissemination area. Dissemination areas are the smallest unit of geography defined by Statistics Canada and include between 400 and 700 persons. Using the 2001 census, income quintiles were determined that adjust for household size and regional differences [9].

Factors associated with enrollment on trial were evaluated using logistic regression analysis and associations were illustrated using odds ratios (OR) with associated 95\% confidence intervals (CIs). Univariate and multiple logistic regression analyses were conducted where multiple regression included all evaluated factors in the model. In order to remove the impact of lack of trial availability, we also conducted a subgroup analysis in which we removed patients in which the reason for non-enrollment was stated to be "No available trial".

Statistical significance was defined as $P$ value $<0.05$. Statistical analysis was conducted using the SAS statistical program (SAS-PC, version 9.4; SAS Institute Inc., Cary, North Carolina).

\section{Results}

Of 10,899 patients identified in CYP-C, 1695 were excluded leaving 9204 that were included in the final analysis. Figure 1 illustrates the flow diagram of patient identification and selection and reasons for exclusion. Table 1 illustrates the demographic characteristics of the study cohort. Among this cohort, 2533 (27.5\%) were enrolled on a therapeutic clinical trial for the initial cancer diagnosis. The number of children enrolled on a clinical trial from POGO and non-POGO centers were $867 / 3447(25.2 \%)$ and $1666 / 5757(28.9 \%)$ respectively $(P<0.0001)$ (data not shown). In comparing those with and without enrollment information available, there was no difference in gender $(P=0.581)$, However, there was a significant difference in diagnosis $(P<0.0001)$ and age group $(P<0.0001)$.

Table 2 illustrates the reasons for non-enrollment collected from the 12 non-Ontario institutions. The most common known reasons for non-enrollment were: "No available trial", 52.2\%; "Physician choice", 11.2\%; and "Not eligible for any trial", 6.5\%. Only 3.7\% of patients were not enrolled on a clinical trial because of refusal to participate. The number not enrolled because of lack of trial availability was similar before and after January 1, 2007 (52.4\% versus 52.0\%). The reason for nonenrollment was not found in the patient chart and was cited as unknown in $23.5 \%$ of cases. Overall, reasons for non-enrollment between the two time periods were significantly different $(P=0.007)$ by Chi square test. When focusing on the proportion with a known reason for non-enrollment, $2105 / 3084$ (68.3\%) were due to no available trial.

Table 3 illustrates the proportion who were enrolled on a trial by underlying oncology diagnosis and illustrates that enrollment rates were highest for patients with acute lymphoblastic leukemia (ALL) (48.8\%) and lowest for patients with astrocytoma (5.3\%). The proportion enrolled on a trial significantly increased after January 1, 2007 for those with ALL, acute myeloid leukemia, and Wilms tumor. However, the proportion enrolled significantly decreased for those with nonHodgkin lymphoma, other lymphomas, Ewing sarcoma, neuroblastoma and ganglioneuroblastoma, ependymoma and other central nervous system tumors.

In univariate analysis, factors significantly associated with enrollment on trial were age at diagnosis, race, underlying diagnosis and distance to the closest tertiary care center (Table 4). In the evaluation of diagnosis, astrocytoma was used as the reference category as these patients had the lowest rate of enrollment. In the multiple regression analysis with all factors included, age was no longer associated with enrollment $(P=0.450)$. Conversely, Asian and Arab/west Asian race remained significantly associated with lower 


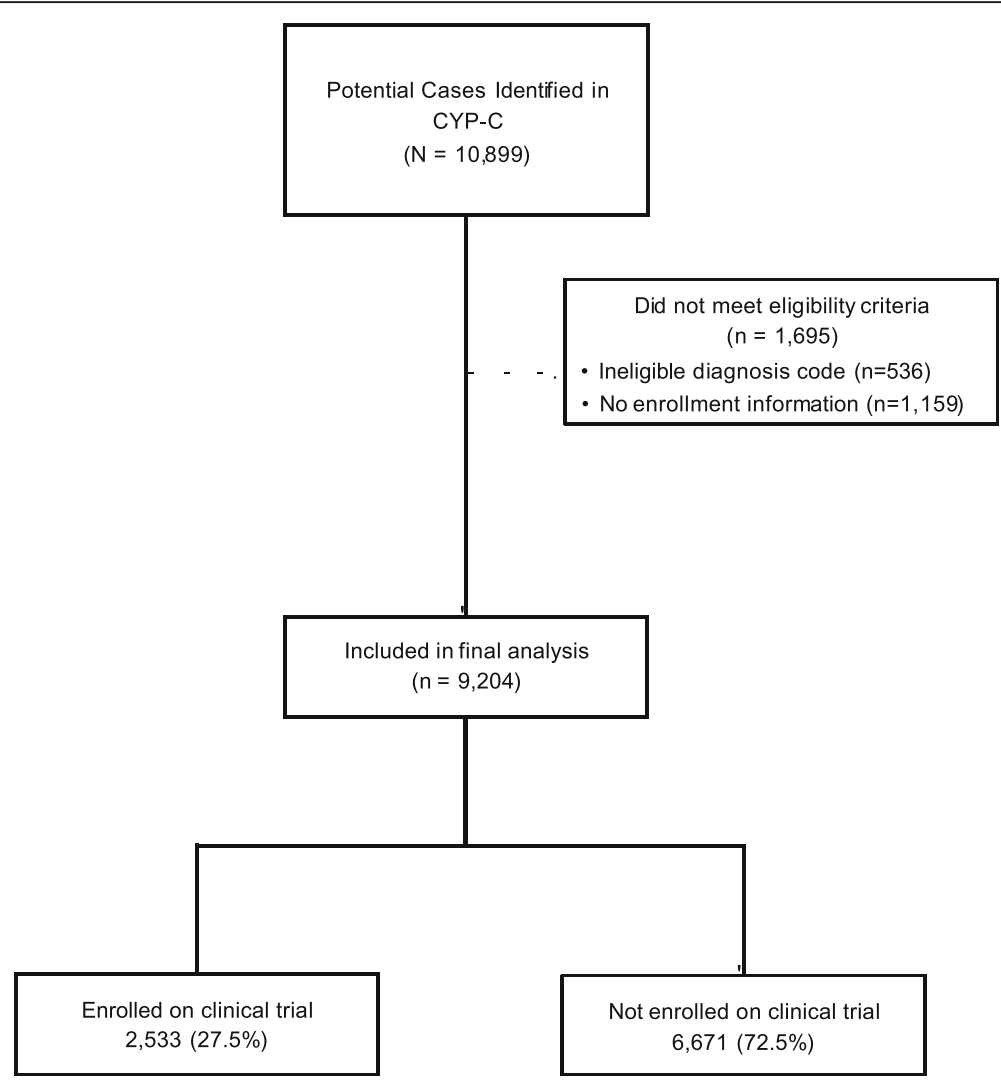

Fig. 1 Flow diagram of case identification and selection

enrollment on trials with OR 0.8 (95\% CI 0.6 to 0.9 ; $P=0.006)$ and $0.7(0.4$ to $0.96 ; P=0.032)$ respectively. In the adjusted model, all evaluated diagnoses were more likely to be enrolled on trials in comparison to children with astrocytoma and more specifically, children with ALL had an almost 18 fold increased odds of trial enrollment compared to children with astrocytoma $(P<0.0001)$. Shorter distance to the nearest tertiary care center remained independently associated with higher enrollment on trials in this multiple regression analysis. A new multiple regression model was then constructed and included site as a covariate. In this analysis, ethnicity $(P=0.0017)$ and diagnosis $(P<0.0001)$ remained significantly associated with enrollment.

We then conducted the subgroup analysis in which multiple regression was repeated after removal of patients in whom non-enrollment reason was stated as "No available trial". Asian and Arab/west Asian race remained significantly associated with lower enrollment on trials with OR $0.6(95 \%$ CI 0.4 to 0.97 ; $P=0.037)$ and OR 0.4 (95\% CI 0.2 to $0.8 ; P=0.004)$ respectively. Children with ALL had a 26 fold increased odds of trial enrollment compared to children with astrocytoma in this subgroup analysis (OR 26.2, 95\% CI 16.8 to $40.7 ; P<0.0001)$.

\section{Discussion}

In this population based study, we found that the proportion of pediatric cancer patients enrolled on a therapeutic trial for the initial diagnosis of cancer was $27.5 \%$. We found that when the reason for non-enrollment was documented, the two most common were lack of trial availability and physician choice. Factors associated with lower enrollment were Asian and Arab/west Asian race, underlying diagnosis and greater distance from the nearest tertiary care hospital.

In trying to place our findings in context to the existing literature, it becomes clear that other studies reporting the number of children enrolled to trials differed in their methodology and approach, with many reporting that more children were enrolled on trials compared with our study. For example, a report from the United Kingdom Children's Cancer Study Group noted that $70 \%$ of all children were enrolled to trials. However, it was not clear whether the denominator reflected children diagnosed when a study was open for accrual, those who were eligible when a study was available, or all 
Table 1 Demographics of the Study Population

\begin{tabular}{|c|c|}
\hline Characteristics & $N=9204$ \\
\hline \multicolumn{2}{|l|}{ Demographic Features } \\
\hline \multicolumn{2}{|l|}{ Age at Diagnosis } \\
\hline$<1$ years & $991(10.8 \%)$ \\
\hline $1-4$ years & 3355 (36.5\%) \\
\hline $5-9$ years & $2324(25.2 \%)$ \\
\hline $10-14$ years & $2534(27.5 \%)$ \\
\hline Male Sex & 4961 (53.9\%) \\
\hline \multicolumn{2}{|l|}{ Race } \\
\hline White & $6169(67.0 \%)$ \\
\hline Asian & $909(9.9 \%)$ \\
\hline Arab/West Asian & $179(1.9 \%)$ \\
\hline Aboriginal & $214(2.3 \%)$ \\
\hline Black & $239(2.6 \%)$ \\
\hline Latin American & $105(1.1 \%)$ \\
\hline Other & $169(1.8 \%)$ \\
\hline Unknown & $1220(13.3 \%)$ \\
\hline \multicolumn{2}{|l|}{ Diagnostic Era } \\
\hline$<2007$ & $4608(50.1 \%)$ \\
\hline$\geq 2007$ & 4596 (49.9\%) \\
\hline \multicolumn{2}{|l|}{ Diagnosis } \\
\hline Leukemia & $2699(29.3 \%)$ \\
\hline Acute lymphoblastic leukemia & $2138(23.2 \%)$ \\
\hline Acute myeloid leukemia & $395(4.3 \%)$ \\
\hline Lymphoma & $962(10.5 \%)$ \\
\hline Hodgkin lymphoma & $400(4.3 \%)$ \\
\hline $\begin{array}{l}\text { Non-Hodgkin lymphoma excluding } \\
\text { Burkitt's lymphoma }\end{array}$ & $340(3.7 \%)$ \\
\hline Burkitt's lymphoma & $162(1.8 \%)$ \\
\hline Solid Tumors & 3187 (34.6\%) \\
\hline Ewing sarcoma & $164(1.8 \%)$ \\
\hline Hepatoblastoma & $139(1.5 \%)$ \\
\hline Neuroblastoma and ganglioneuroblastoma & $734(8.0 \%)$ \\
\hline Osteosarcoma & $207(2.2 \%)$ \\
\hline Rhabdomyosarcoma & $273(3.0 \%)$ \\
\hline Wilms tumor & $424(4.6 \%)$ \\
\hline Central Nervous System Tumors & $2307(25.1 \%)$ \\
\hline Astrocytoma & $982(10.7 \%)$ \\
\hline Ependymoma & $197(2.1 \%)$ \\
\hline Medulloblastoma & $172(1.9 \%)$ \\
\hline \multicolumn{2}{|l|}{ Socioeconomic Factors } \\
\hline $\begin{array}{l}\text { Median Km to Nearest Tertiary } \\
\text { Care Center (Interquartile Range) }\end{array}$ & $30.0(12.2$ to 112.4$)$ \\
\hline \multicolumn{2}{|l|}{ Income quintile } \\
\hline 1 (lowest) & $1732(18.8 \%)$ \\
\hline 2 & $1759(19.1 \%)$ \\
\hline
\end{tabular}

Table 1 Demographics of the Study Population (Continued)

\begin{tabular}{ll}
3 & $1814(19.7 \%)$ \\
4 & $1843(20.0 \%)$ \\
5 (highest) & $1893(20.6 \%)$ \\
Missing & $163(1.8 \%)$ \\
\hline
\end{tabular}

children diagnosed with cancer [10]. A report concluding that $86.1 \%$ of patients $\leq 21$ years of age were enrolled on any trial excluded patients who were diagnosed when a trial was not available [5]. Another study described that $73 \%$ of potentially eligible patients with leukemia were enrolled on a trial with the assumption that a trial was available throughout the time frame of evaluation [11].

When studies evaluated a similar metric to ours, namely the proportion of all children diagnosed with cancer enrolled on a therapeutic clinical trial, similar findings were observed. For example, Dodgshun et al. found that among children $\leq 16$ years of age with cancer diagnosed between 2009 and 2010 in New Zealand, $27.5 \%$ were enrolled on a trial [12]. Single center studies from Seattle [13] and Pittsburgh [4] demonstrated that $48.8 \%$ and $38 \%$ were enrolled on therapeutic trials.

We found that the two most common reasons cited for non-enrollment were lack of trial availability and physician decision. Unfortunately, we do not know from the data whether lack of trial availability reflected lack of any trial for that diagnosis, or whether a trial was available but not activated at the center because of regulatory/ethics barriers or delays, or whether the center had chosen not to open an available study. This finding suggests that if trial enrollment is important, barriers to having trials available should be identified and mechanisms to facilitate and expedite trial activation should be implemented. The high proportion of physicians deciding to not enroll children on trials is interesting and should be explored further to better understand reasons for not offering eligible children a clinical trial. It was also surprising and encouraging that patient refusal was an uncommon reason for non-participation. However, this figure does not imply that patients understand the consenting process or that they are later satisfied with their decision. These are important research questions.

Risk factors for non-enrollment previously identified have been older age $[5,14,15]$, diagnosis of lymphoma and brain tumor [12] and Hispanic patients or those with Spanish-speaking parents [5]. Interestingly, our study had different findings with age not being a significant factor in the adjusted model, which may be the result of most children with ALL being younger. However, we found Asian race was negatively associated with trial enrollment, which is a novel finding. The association between underlying diagnosis and non-enrollment does not solely reflect the availability of clinical trials as 
Table 2 Reasons for Non-Enrollment on Trials in 12 Non-Ontario Institutions ${ }^{a}$

\begin{tabular}{|c|c|c|c|}
\hline & Total & $<2007$ & $\geq 2007$ \\
\hline & $N=4033$ & $N=2007$ & $N=2026$ \\
\hline Language Barrier, Trial Not Offered & $22(0.5 \%)$ & $13(0.6 \%)$ & $9(0.4 \%)$ \\
\hline No Available Trial & $2105(52.2 \%)$ & $1051(52.4 \%)$ & $1054(52.0 \%)$ \\
\hline Not Eligible for Any Trial & $261(6.5 \%)$ & $136(6.8 \%)$ & $125(6.2 \%)$ \\
\hline Physician Choice & $452(11.2 \%)$ & $189(9.4 \%)$ & $263(13.0 \%)$ \\
\hline Refused Therapy & $20(0.5 \%)$ & $12(0.6 \%)$ & $8(0.4 \%)$ \\
\hline Refused to Participate in Proposed Trial & $151(3.7 \%)$ & $67(3.3 \%)$ & $84(4.1 \%)$ \\
\hline Other & $73(1.8 \%)$ & $36(1.8 \%)$ & $37(1.8 \%)$ \\
\hline Unknown & 949 (23.5\%) & $503(25.1 \%)$ & $446(22.0 \%)$ \\
\hline
\end{tabular}

${ }^{a}$ In 58 cases, treatment plan was not available and thus, reason for non-enrollment was not required

shown by our subgroup analysis in which we removed patients in whom lack of trial availability was stated as the reason for non-enrollment.

The strengths of this study were its population-based nature and the consistent collection of reasons for nonenrollment from the 12 non-Ontario centers. However, these results must be interpreted in light of its limitations. First, we did not describe outcomes of patients enrolled and not enrolled on clinical trials. We felt that describing outcomes was outside the scope of this paper as each diagnosis will need to be addressed separately since consideration of confounding variables and risk stratification will differ by diagnosis type. Second, we only evaluated clinical trial enrollment at initial

Table 3 Proportion Enrolled on Trial by Diagnosis

\begin{tabular}{|c|c|c|c|c|}
\hline & \multirow[t]{2}{*}{ Total } & \multirow{2}{*}{$\begin{array}{l}<2007 \\
N=4608\end{array}$} & \multirow{2}{*}{$\begin{array}{l}\geq 2007 \\
N=4596\end{array}$} & \multirow[t]{2}{*}{$P$ Value* } \\
\hline & & & & \\
\hline Leukemia & $1199 / 2699(44.4 \%)$ & $547 / 1362(40.2 \%)$ & $652 / 1337(48.8 \%)$ & \\
\hline Acute lymphoblastic leukemia & 1043/2138 (48.8\%) & $484 / 1075$ (45.0\%) & $559 / 1063(52.6 \%)$ & 0.0006 \\
\hline Acute myeloid leukemia & 138/395 (34.9\%) & $50 / 192(26.0 \%)$ & $88 / 203(43.3 \%)$ & 0.0005 \\
\hline Other leukemias & 18/166 (10.8\%) & 13/95 (13.7\%) & $5 / 71(7.0 \%)$ & 0.267 \\
\hline Lymphoma & 270/962 (28.1\%) & 167/504 (33.1\%) & $103 / 458(22.5 \%)$ & \\
\hline Hodgkin lymphoma & $130 / 400(32.5 \%)$ & $61 / 200(30.5 \%)$ & $69 / 200(34.5 \%)$ & 0.455 \\
\hline $\begin{array}{l}\text { Non-Hodgkin lymphoma excluding } \\
\text { Burkitt's lymphoma }\end{array}$ & $90 / 340(26.5 \%)$ & $64 / 180(35.6 \%)$ & 26/160 (16.3\%) & $<0.0001$ \\
\hline Burkitt's lymphoma & $37 / 162(22.8 \%)$ & $31 / 91(34.1 \%)$ & $6 / 71(8.5 \%)$ & 0.0002 \\
\hline Other lymphomas & $13 / 60(21.7 \%)$ & 11/33 (33.3\%) & $2 / 27(7.4 \%)$ & 0.035 \\
\hline Solid Tumors & $827 / 3187(25.9 \%)$ & 435/1556 (28.0\%) & $392 / 1631$ (24.0\%) & \\
\hline Ewing sarcoma & 63/164 (38.4\%) & $39 / 82(47.6 \%)$ & 24/82 (29.3\%) & 0.025 \\
\hline Hepatoblastoma & $22 / 139(15.8 \%)$ & 15/70 (21.4\%) & $7 / 69(10.1 \%)$ & 0.112 \\
\hline Neuroblastoma and ganglioneuroblastoma & 237/734 (32.3\%) & $140 / 363(38.6 \%)$ & $97 / 371(26.1 \%)$ & 0.0004 \\
\hline Osteosarcoma & $78 / 207$ (37.7\%) & $35 / 98(35.7 \%)$ & $43 / 109$ (39.4\%) & 0.682 \\
\hline Rhabdomyosarcoma & $121 / 273(44.3 \%)$ & $68 / 135(50.4 \%)$ & $53 / 138(38.4 \%)$ & 0.062 \\
\hline Wilms tumor & $160 / 424(37.7 \%)$ & $66 / 204(32.4 \%)$ & $94 / 220(42.7 \%)$ & 0.036 \\
\hline Other solid tumors & $146 / 1246(11.7 \%)$ & $72 / 604(11.9 \%)$ & $74 / 642(11.5 \%)$ & 0.898 \\
\hline Central Nervous System Tumors & 237/2307 (10.3\%) & 134/1167 (11.5\%) & $103 / 1140(9.0 \%)$ & \\
\hline Astrocytoma & $52 / 982(5.3 \%)$ & $26 / 508(5.1 \%)$ & 26/474 (5.5\%) & 0.909 \\
\hline Ependymoma & 38/197 (19.3\%) & $24 / 93(25.8 \%)$ & 14/104 (13.5\%) & 0.044 \\
\hline Medulloblastoma & $36 / 172(20.9 \%)$ & 15/88 (17.0\%) & 21/84 (25.0\%) & 0.274 \\
\hline Other central nervous system tumors & 111/956 (11.6\%) & $69 / 478(14.4 \%)$ & $42 / 478(8.8 \%)$ & 0.009 \\
\hline
\end{tabular}

${ }^{*} P$ values by $C h i$ square test 
Table 4 Univariate and Multiple Logistic Regression Evaluating Factors Associated with Enrollment

\begin{tabular}{|c|c|c|c|c|c|c|c|}
\hline \multirow[t]{2}{*}{ Characteristics } & \multirow[t]{2}{*}{$\begin{array}{l}\text { Enrolled } \\
N=2533\end{array}$} & \multirow[t]{2}{*}{$\begin{array}{l}\text { Not Enrolled } \\
N=6671\end{array}$} & \multirow[t]{2}{*}{$\begin{array}{l}\text { Percent } \\
\text { Enrolled }\end{array}$} & \multicolumn{2}{|c|}{$\begin{array}{l}\text { Univariate Regression } \\
\text { Analysis }\end{array}$} & \multicolumn{2}{|c|}{$\begin{array}{l}\text { Multiple Regression } \\
\text { Analysis }\end{array}$} \\
\hline & & & & OR $(95 \% \mathrm{Cl})$ & $P$ Value* & OR $(95 \% \mathrm{Cl})$ & $P$ Value* \\
\hline \multicolumn{8}{|l|}{ Demographic Features } \\
\hline Age at Diagnosis & & & & & $<0.0001$ & & 0.450 \\
\hline$<1$ years & $216(8.5 \%)$ & $775(11.6 \%)$ & 21.8 & REF & & REF & \\
\hline $1-4$ years & $1078(42.6 \%)$ & 2277 (34.1\%) & 32.1 & 1.7 (1.4 to 2.0$)$ & $<0.0001$ & 1.1 (0.9 to 1.4$)$ & 0.213 \\
\hline $5-9$ years & $620(24.5 \%)$ & $1704(25.5 \%)$ & 26.7 & 1.3 (1.1 to 1.6$)$ & 0.003 & $1.0(0.8$ to 1.3$)$ & 0.711 \\
\hline $10-14$ years & $619(24.4 \%)$ & 1915 (28.7\%) & 24.4 & $1.2(1.0$ to 1.4$)$ & 0.099 & $1.0(0.8$ to 1.3$)$ & 0.714 \\
\hline \multicolumn{8}{|l|}{ Sex } \\
\hline Male & $1405(55.5 \%)$ & $3556(53.3 \%)$ & 28.3 & 1.1 (1.0 to 1.2$)$ & 0.064 & $1.0(0.9$ to 1.1$)$ & 0.660 \\
\hline Female & $1128(44.5 \%)$ & 3115 (46.7\%) & 26.6 & REF & & & \\
\hline Race & & & & & 0.0003 & & 0.033 \\
\hline White & $1793(70.8 \%)$ & $4376(65.6 \%)$ & 29.1 & REF & & REF & \\
\hline Asian & $218(8.6 \%)$ & $691(10.4 \%)$ & 24.0 & 0.8 (0.7 to 0.9$)$ & 0.002 & 0.8 (0.6 to 0.9$)$ & 0.006 \\
\hline Arab/West Asian & $37(1.5 \%)$ & $142(2.1 \%)$ & 20.7 & $0.6(0.4$ to 0.9$)$ & 0.015 & 0.7 (0.4 to 0.96$)$ & 0.032 \\
\hline Aboriginal & $53(2.1 \%)$ & $161(2.4 \%)$ & 24.8 & $0.8(0.6$ to 1.1$)$ & 0.174 & $0.8(0.5$ to 1.1$)$ & 0.189 \\
\hline Black & $66(2.6 \%)$ & $173(2.6 \%)$ & 27.6 & $0.9(0.7$ to 1.2$)$ & 0.628 & 1.1 (0.8 to 1.5$)$ & 0.654 \\
\hline Latin American & $25(1.0 \%)$ & $80(1.2 \%)$ & 23.8 & $0.8(0.5$ to 1.2$)$ & 0.241 & 0.8 (0.5 to 1.4$)$ & 0.485 \\
\hline Other & $50(2.0 \%)$ & $119(1.8 \%)$ & 29.6 & $1.0(0.7$ to 1.4$)$ & 0.883 & 1.1 (0.7 to 1.6$)$ & 0.697 \\
\hline Unknown & $291(11.5 \%)$ & $929(13.9 \%)$ & 23.9 & $0.8(0.7$ to 0.9$)$ & 0.0002 & 1.1 (0.9 to 1.2$)$ & 0.488 \\
\hline \multicolumn{8}{|l|}{ Diagnostic Era } \\
\hline$<2007$ & $1283(50.7 \%)$ & 3325 (49.8\%) & 27.8 & $1.0(0.9$ to 1.1$)$ & 0.488 & $1.0(0.9$ to 1.1$)$ & 0.966 \\
\hline$\geq 2007$ & $1250(49.3 \%)$ & $3346(50.2 \%)$ & 27.2 & REF & & & \\
\hline Diagnosis & & & & & $<0.0001$ & & $<0.0001$ \\
\hline \multicolumn{8}{|l|}{ Leukemia } \\
\hline Acute lymphoblastic leukemia & $1043(41.2 \%)$ & 1095 (16.4\%) & 48.8 & $\begin{array}{l}17.0(12.7 \text { to } \\
22.8)\end{array}$ & $<0.0001$ & $\begin{array}{l}17.7(12.9 \text { to } \\
24.4)\end{array}$ & $<0.0001$ \\
\hline Acute myeloid leukemia & $138(5.4 \%)$ & 257 (3.9\%) & 34.9 & 9.6 (6.8 to 13.6$)$ & $<0.0001$ & $9.0(6.2$ to 13.3$)$ & $<0.0001$ \\
\hline Other leukemia & $18(0.7 \%)$ & $148(2.2 \%)$ & 10.8 & $2.2(1.2$ to 3.8$)$ & 0.007 & 2.2 (1.2 to 4.2$)$ & 0.012 \\
\hline \multicolumn{8}{|l|}{ Lymphoma } \\
\hline Hodgkin lymphoma & $130(5.1 \%)$ & $270(4.0 \%)$ & 32.5 & 8.6 (6.1 to 12.2 ) & $<0.0001$ & $10.2(7.0$ to 15.0$)$ & $<0.0001$ \\
\hline $\begin{array}{l}\text { Non-Hodgkin lymphoma excluding } \\
\text { Burkett's lymphoma }\end{array}$ & $90(3.6 \%)$ & $250(3.7 \%)$ & 26.5 & 6.4 (4.5 to 9.3 ) & $<0.0001$ & $7.4(4.9$ to 11.0$)$ & $<0.0001$ \\
\hline Burkitt's lymphoma & $37(1.5 \%)$ & $125(1.9 \%)$ & 22.8 & 5.3 (3.3 to 8.4 ) & $<0.0001$ & 6.0 (3.7 to 9.8) & $<0.0001$ \\
\hline Other lymphoma & $13(0.5 \%)$ & $47(0.7 \%)$ & 21.7 & 4.9 (2.5 to 9.7$)$ & $<0.0001$ & 6.7 (3.3 to 13.6$)$ & $<0.0001$ \\
\hline \multicolumn{8}{|l|}{ Solid Tumors } \\
\hline Ewing sarcoma & $63(2.5 \%)$ & $101(1.5 \%)$ & 38.4 & 11.2 (7.3 to 17.0$)$ & $<0.0001$ & 13.6 (8.6 to 21.3 ) & $<0.0001$ \\
\hline Hepatoblastoma & $22(0.9 \%)$ & $117(1.8 \%)$ & 15.8 & 3.4 (2.0 to 5.7$)$ & $<0.0001$ & 3.9 (2.2 to 6.8 ) & $<0.0001$ \\
\hline $\begin{array}{l}\text { Neuroblastoma and } \\
\text { ganglioneuroblastoma }\end{array}$ & $237(9.4 \%)$ & $497(7.5 \%)$ & 32.3 & 8.5 (6.2 to 11.7$)$ & $<0.0001$ & 9.3 (6.5 to 13.2$)$ & $<0.0001$ \\
\hline Osteosarcoma & $78(3.1 \%)$ & $129(1.9 \%)$ & 37.7 & $10.8(7.3$ to 16.1$)$ & $<0.0001$ & 12.7 (8.2 to 19.8) & $<0.0001$ \\
\hline Rhabdomyosarcoma & $121(4.8 \%)$ & $152(2.3 \%)$ & 44.3 & 14.2 (9.9 to 20.6) & $<0.0001$ & 16.3 (11.0 to 24.4$)$ & $<0.0001$ \\
\hline Wilms tumor & $160(6.3 \%)$ & $264(4.0 \%)$ & 37.7 & 10.8 (7.7 to 15.3$)$ & $<0.0001$ & 11.8 (8.2 to 17.2 ) & $<0.0001$ \\
\hline Other solid tumor & $146(5.8 \%)$ & $1100(16.5 \%)$ & 11.7 & 2.4 (1.7 to 3.3$)$ & $<0.0001$ & 2.6 (1.8 to 3.7 ) & $<0.0001$ \\
\hline \multicolumn{8}{|l|}{ CNS Tumors } \\
\hline Astrocytoma & $52(2.1 \%)$ & 930 (13.9\%) & 5.3 & REF & & & \\
\hline
\end{tabular}


Table 4 Univariate and Multiple Logistic Regression Evaluating Factors Associated with Enrollment (Continued)

\begin{tabular}{|c|c|c|c|c|c|c|c|}
\hline Ependymoma & $38(1.5 \%)$ & $159(2.4 \%)$ & 19.3 & 4.3 (2.7 to 6.7$)$ & $<0.0001$ & 4.5 (2.7 to 7.3$)$ & $<0.0001$ \\
\hline Medulloblastoma & $36(1.4 \%)$ & $136(2.0 \%)$ & 20.9 & 4.7 (3.0 to 7.5$)$ & $<0.0001$ & 4.6 (2.8 to 7.6$)$ & $<0.0001$ \\
\hline Other brain tumor & $111(4.4 \%)$ & 845 (12.7\%) & 11.6 & 2.3 (1.7 to 3.3 ) & $<0.0001$ & 2.6 (1.8 to 3.7 ) & $<0.0001$ \\
\hline \multicolumn{8}{|l|}{ Socioeconomic Factors } \\
\hline $\begin{array}{l}\text { Median Km to Nearest Tertiary } \\
\text { Care Center (Interquartile Range) }\end{array}$ & $\begin{array}{l}28.0(12.4 \text { to } \\
99.4)\end{array}$ & $\begin{array}{l}30.9(12.0 \text { to } \\
118.2)\end{array}$ & & $\begin{array}{l}\text { Per } 100 \mathrm{~km} \\
0.96(0.94 \text { to } \\
0.98)\end{array}$ & $<0.0001$ & $\begin{array}{l}\text { Per } 100 \mathrm{~km} \\
0.96(0.94 \text { to } \\
0.98)\end{array}$ & 0.0005 \\
\hline Income quintile & & & & & 0.523 & & 0.908 \\
\hline 1 (lowest) & $452(17.8 \%)$ & $1280(19.2 \%)$ & 26.1 & REF & & REF & \\
\hline 2 & 489 (19.3\%) & $1270(19.0 \%)$ & 27.8 & 1.1 (0.9 to 1.3$)$ & 0.257 & 1.1 (0.9 to 1.3 ) & 0.445 \\
\hline 3 & $508(20.1 \%)$ & 1306 (19.6\%) & 28.0 & $1.1(1.0$ to 1.3$)$ & 0.201 & 1.0 (0.9 to 1.2 ) & 0.718 \\
\hline 4 & $522(20.6 \%)$ & $1321(19.8 \%)$ & 28.3 & 1.1 (1.0 to 1.3$)$ & 0.135 & 1.0 (0.9 to 1.2$)$ & 0.861 \\
\hline 5 (highest) & $539(21.3 \%)$ & $1354(20.3 \%)$ & 28.5 & 1.1 (1.0 to 1.3$)$ & 0.109 & 1.0 (0.8 to 1.2$)$ & 0.900 \\
\hline
\end{tabular}

* $P$ value by logistic regression

Abbreviations: $O R$ odds ratio, $C l$ confidence interval, $R E F$ reference

cancer diagnosis and not at refractory disease or relapse, another important future research gap. Third, an important limitation of our study is that we did not include adolescent and young adult patients (AYA) in our study. This is important as several studies have identified that AYA patients have lower rates of enrollment on clinical trials. [5, 14, 15] Our study suggests that in general, younger patients have poor rates of enrollment to trials; this implies that AYA enrollments may even be worse than previously thought when evaluated on a population basis. Fourth, an important limitation is that we excluded more than $10 \%$ of the sample because of unknown trial status. This exclusion may mean that our rates of enrollment are falsely high and is an important fact to stress when citing these results. Also, there was a high rate of missing reasons for failure to enroll on a trial, thus meaning that factors less likely to be recorded in the medical records, such as physician preference, may be under-represented. However, factors such as patient refusal should have been well documented and are thus unlikely to be biased. Finally, we found that those with missing enrollment information were significantly different by age and diagnosis, thus potentially limiting the generalizability of our findings (data not shown).

\section{Conclusions}

In conclusion, in Canada, 27.5\% of children with cancer are enrolled onto therapeutic clinical trials and lack of an available trial is the most common stated reason contributing to non-enrollment. Future research should better understand reasons for lack of trial availability and physician preferences to not offer trials.

\section{Abbreviations}

ALL: Acute Lymphoblastic Leukemia; AYA: Adolescent and Young Adult; CYP-C: Cancer in Young People in Canada; ICCC: International Classification of Childhood Cancer; OR: Odds Ratio; POGO: Pediatric Oncology Group of
Ontario; POGONIS: Pediatric Oncology Group of Ontario Networked Information System

\section{Acknowledgements}

The authors gratefully acknowledge the contributions of study participants, participating pediatric oncology centers, members of the Cancer in Young People in Canada (CYP-C) Management and Steering Committees, the Pediatric Oncology Group of Ontario (POGO) and the five POGO Hospital Partners. The CYP-C is fully funded by the Public Health Agency of Canada. We wish to thank Mark Bernstein MD, Kimberly Hutchings MSc and Debjani Mitra MSc for their early work in the development of the CYP-C national database. We also wish to thank all data managers at the 17 CYP-C sites for their dedicated work in maintaining CYP-C data quality and Jay Onysko MA for providing important input into the CYP-C program.

Funding

None declared.

\section{Availability of data and materials}

The datasets supporting the conclusions of this article are available at no cost in Cancer in Young People in Canada (CYP-C), a national pediatric cancer population-based database (http://www.phac-aspc.gc.ca/cd-mc/cancer/childhood_cancer-cancer_enfants-eng.php). CYP-C is fully funded and managed by the Public Health Agency of Canada in partnership with the C17 Council, the network of all the seventeen children's cancer hospitals across the country.

\section{Authors' contributions}

$J P, R B$, and LS developed the study concepts and design and were responsible for quality control of data and algorithms. JP, RB, REB, ASC, DD, $\mathrm{KK}, \mathrm{EM}, \mathrm{AR}, \mathrm{DS}, \mathrm{CS}, \mathrm{DRS}, \mathrm{T}$, and LS participated in data acquisition. JP and LS did all of the statistical analysis. LS was responsible for the preparation of the manuscript and all authors edited and reviewed the final manuscript. All authors have approved of this final version of the manuscript for publication and agree to be accountable for all aspects of the work.

\section{Competing interests}

The authors declare that they have no competing interests

\section{Consent for publication \\ Not applicable.}

\section{Ethics approval and consent to participate}

Approval to use data in CYP-C for the purpose of this research was granted from the CYP-C Management Committee and POGO. Research Ethics Board approval was obtained from The Hospital for Sick Children. The requirement for informed consent was waived given the retrospective nature of the data. 


\section{Publisher's Note}

Springer Nature remains neutral with regard to jurisdictional claims in published maps and institutional affiliations.

\section{Author details}

${ }^{1}$ Pediatric Oncology Group of Ontario, 480 University Avenue, Suite 1014, Toronto M5G 1V2, Canada. ${ }^{2}$ C17 Research Council, ECHA, 11405-87 Avenue, Edmonton T6G 1C9, Canada. ${ }^{3}$ Montreal Children's Hospital, 1001 Boulevard Decarie, Montreal H4A 3J1, Canada. ${ }^{4}$ Centre Hospitalier Universitaire Sainte-Justine, 3175 Chemin Cote Sainte-Catherine, Montreal H1T 3C5, Canada. ${ }^{5}$ BC Children's Hospital, 4480 Oak Street Room B315, Vancouver V6H 3V4, Canada. ${ }^{6}$ IWK Health Centre, 5850/5950 University Avenue, Halifax B3K 6R8, Canada. ${ }^{7}$ Centre Hospitalier Universitaire de Quebec-Universite Laval, 2705 Boulevard Laurier, Quebec City G1V 4G2, Canada. ${ }^{8}$ Royal University Hospital, 103 Hospital Drive, Saskatoon S7N 0W8, Canada. ${ }^{9}$ Alberta Children's Hospital, 2888 Shaganappi Trail N.W, Calgary T3B 6A8, Canada. ${ }^{10}$ The Hospital for Sick Children, 555 University Avenue, Toronto M5G 1X8, Canada. ${ }^{11}$ Child Health Evaluative Sciences, 686 Bay Street, Toronto M5G 0A4, Canada.

Received: 4 January 2017 Accepted: 26 May 2017

Published online: 05 June 2017

\section{References}

1. Peppercorn JM, Weeks JC, Cook EF, Joffe S. Comparison of outcomes in cancer patients treated within and outside clinical trials: conceptual framework and structured review. Lancet. 2004;363(9405):263-70.

2. Dix D, Aplenc R, Bowes L, Cellot S, Ethier M-C, Feusner J, et al. Impact of registration on clinical trials on infection risk in pediatric acute myeloid leukemia. Int J Cancer. 2016;138(7):1785-91.

3. What are the possible benefits and risks of clinical trials? [https://www.nhlbi. nih.gov/studies/clinicaltrials/benefitsrisks]. Accessed 25 Apr 2017.

4. Shaw PH, Ritchey AK. Different rates of clinical trial enrollment between adolescents and young adults aged 15 to 22 years old and children under 15 years old with cancer at a children's hospital. J Pediatr Hematol Oncol. 2007:29(12):811-4

5. Aristizabal P, Singer J, Cooper R, Wells KJ, Nodora J, Milburn M, et al. Participation in pediatric oncology research protocols: racial/ethnic, language and age-based disparities. Pediatr Blood Cancer. 2015;62(8):1337-44.

6. What is a Clinical Trial? [https://childrensoncologygroup.org/index.php/ what-is-a-clinical-trial]. Accessed 20 Sept 2016.

7. Steliarova-Foucher E, Stiller C, Lacour B, Kaatsch P. International Classification of Childhood cancer, third edition. Cancer. 2005;103(7):1457-67.

8. Greenberg ML, Barr RD, DiMonte B, McLaughlin E, Greenberg C. Childhood cancer registries in Ontario, Canada: lessons learned from a comparison of two registries. Int J Cancer. 2003;105(1):88-91.

9. Borugian MJ, Spinelli JJ, Mezei G, Wilkins R, Abanto Z, McBride ML. Childhood leukemia and socioeconomic status in Canada. Epidemiology. 2005:16(4):526-31.

10. Ablett S, Pinkerton CR. United Kingdom Children's cancer study G: recruiting children into cancer trials-role of the United Kingdom Children's cancer study group (UKCCSG). Br J Cancer. 2003;88(11):1661-5.

11. Krailo MD, Bernstein L, Sullivan-Halley J, Hammond GD. Patterns of enrollment on cooperative group studies. An analysis of trends from the Los Angeles County cancer surveillance program. Cancer. 1993;71(10 Suppl):3325-30.

12. Dodgshun AJ, De Silva MP, Bradbeer P, Cross S. Enrollment in clinical cancer trials: how are we doing and what are the obstacles to improving enrollment rates? A 2-year retrospective review of pediatric cancer trial enrollment in New Zealand. J Pediatr Hematol Oncol. 2014;36(8):630-4.

13. Koschmann C, Thomson B, Hawkins DS. No evidence of a trial effect in newly diagnosed pediatric acute lymphoblastic leukemia. Arch Pediatr Adolesc med. 2010;164(3):214-7.

14. Downs-Canner S, Shaw PH. A comparison of clinical trial enrollment between adolescent and young adult (AYA) oncology patients treated at affiliated adult and pediatric oncology centers. J Pediatr Hematol Oncol. 2009;31(12):927-9.

15. Bleyer WA. Cancer in older adolescents and young adults: epidemiology, diagnosis, treatment, survival, and importance of clinical trials. Med Pediatr Oncol. 2002;38(1):1-10.

\section{Submit your next manuscript to BioMed Central and we will help you at every step:}

- We accept pre-submission inquiries

- Our selector tool helps you to find the most relevant journal

- We provide round the clock customer support

- Convenient online submission

- Thorough peer review

- Inclusion in PubMed and all major indexing services

- Maximum visibility for your research

Submit your manuscript at www.biomedcentral.com/submit
Biomed Central 